\title{
Chronic Pain has become a Chronic Problem in Norway. What are we doing Wrong? A Report from a Norwegian Pain Clinic
}

\author{
HervikJ* and Stub T \\ Vestfold Hospital Trust, Norway \\ The Arctic University of Norway, National Research \\ Centre for Complementary and Alternative Medicine, \\ Norway \\ *Corresponding author: J ill Hervik, Vestfold Hospital \\ Trust, Physiotherapist/ Acupuncturist, Norway
}

Received: March 22, 2021; Accepted: April 09, 2021;

Published: April 16, 2021

\section{Pain in Norway}

Chronic pain occurs in around 20\% of European adults [1], affecting 100 million people. In Norway $30 \%$ of the population suffer from chronic pain [2]. Reasons for why Norwegians have such a high incidence of chronic pain is not known. Chronic pain has been associated with socio-economic deprivation [3]. However, the World Bank has declared Norway the richest country in the world [4]. All residents are covered by the National Insurance Scheme. Private medical insurance is limited and most hospitals are public. Outpatient care and medicines used in chronic diseases are usually heavily subsidized or free. Is it possible that these support systems and the provision of sick pay paradoxically reduce motivation in individuals to increase levels of activity, and reduce the use of medication, thereby delaying a return to work?

\section{What is Pain?}

The International Association for the Study of Pain [5] defines pain as an unpleasant sensory and emotional experience associated with, or resembling that associated with, actual or potential tissue damage. It becomes chronic when it lasts more than 3 months. Whereas acute pain usually resolves itself and is responsive to treatment, chronic pain is often resistant to treatment and continues long after the cause is healed. Pain is subjective, psychophysiological aspects determine what it means for each individual. The understanding of pain is influenced by many aspects, including health workers, who with a range of diagnostic and treatment options, and with different attitudes and communication skills, have the ability to both reduce and increase pain.

\section{When Pain Becomes Political}

A systematic review of literature from 7 different European countries analysing policy environment affecting patients suffering from pain, found that that chronic pain is not prioritized through coordinated national plans [6]. Also, although clinical guidelines are generally established, regarding diagnosis and treatment, application was often delayed and limited. This study and the rising number of chronic pain sufferers highlights the need for investigation and discussion into the area of pain policy, including assessment of why our current approach of pain prevention, diagnosis and management does not seem to be working. Although science has increased the understanding of pain related mechanisms, this information has not been successfully utilized clinically by health systems.

\section{Norwegians are in Pain}

The percentage of Norwegians living with pain is $10 \%$ higher than the average in Europe. Corresponding figures in the other Scandinavian countries are 16-19 \% [1]. Musculoskeletal diseases are the most common cause of chronic pain in Norway and are the main diagnosis in $38 \%$ of doctor-certified sick leave [7] and $28 \%$ of disability benefit cases [8]. The incidence of chronic pain has increased slightly in recent years [2]. Reassessment of preventive interventions and pain therapy appears to be long overdue.

Multi-disciplinary pain clinics have been established at the main Norwegian hospitals during the last 30 years. Guidelines from the Department of Health dictate that pain clinics should be consulted when complicated pain presents, and in situations where the clinic has expertise [9].

\section{Psyche and Soma}

Although it is widely accepted that pain is a subjective experience and therefore has a psychological aspect there is still a reluctance to acknowledge that psyche and soma go hand in hand. Patients still seem to want a somatic explanation for their condition. Unfortunately, somatic explanations for chronic pain often carry more weight in insurance and disability claims. Many studies have demonstrated a relationship between anxiety, depression and chronic pain, where pain can provoke psychological symptoms and visa-versa [10]. Traditional Western medicine even separates the body into areas and systems, an approach unsuited to chronic pain that often moves about and involves several bodily systems.

\section{Up to Date}

Up to date [11], a web site that synthesizes the most recent medical information into evidence-based clinical recommendations, states that the cause and type of chronic pain, (neuropathic, nociceptive and centralized pain) should first be identified. Regarding treatment the authors suggest that initial therapy of non-cancer pain should start with nonpharmacologic therapy. Suggestions include selfmanagement education, behavioural health support, sleep hygiene and physical rehabilitation therapies. These types of active therapies aim to improve function, not just reduce pain, and encourage patients to engage in their own care. The use of passive interventions, such as acupuncture or spinal manipulation, as adjunctive treatments during symptom flares is recommended. Further, the authors often 
prescribe non-traditional complementary and integrative health therapies such as mindfulness, hypnosis, biofeedback and massage therapy due to emerging evidence that supports their efficacy and safety. Only when these interventions do not provide an adequate degree of pain reduction and increase in function, are multi-targeted pharmacological therapies considered.

\section{Out of Date}

The Up to Date model is not generally followed in Norway. Conventional medical treatment with drugs is still often first-line pain therapy, despite the Norwegian Medicines Agency receiving 5 623 reports of adverse effects in 2018, where $31 \%$ were classified as severe [12]. The focus is mainly on pain reduction, measured using the visual analogue scale, functional indexes and qualitative assessments are rarely incorporated. Active therapy and psychological approaches are often added when efficacy of medicines is inadequate. Alternative treatment methods are usually only considered as a last resort.

Apart from acupuncture, complementary and alternative treatments have not been used to treat pain in Norwegian hospitals. Acupuncture has been used in a handful of hospital pain clinics during the last 30 years, where it is presently being phased out. The Department of Health heavily subsidizes treatments in hospital outpatient departments, it stopped subsidizing acupuncture treatment at the start of 2021. Other types of treatments with little or no evidence and with a higher risk profile, continue to be used, including intravenous infusions with lidocaine $[13,14]$ or ketamine [15], capsaicin treatments [16] and trigger point injections with local anaesthetic [17]. The restrictions regarding acupuncture were implemented despite the Minister of Health and Care Services calling on Health Trusts to provide drug-free treatment options, and guidelines from the Department of Health stating that pain clinics should be consulted where expertise is found, and where treatment methods are not available in the community.

\section{There is Nothing Exotic about Acupuncture}

Acupuncture is a holistic, inexpensive, evidence-based treatment with a low risk profile, and it is a good alternative or supplement to drugs and other therapies. According to the Cochrane Collaboration, acupuncture is a promising treatment for back, neck and pelvic pain [18], as well as for headaches [19]. The World Health Organization (WHO) recommends acupuncture for 28 different conditions [20]. The UK National Institute for Health and Care Excellence [21] recently published new draft guidelines for the treatment of chronic primary pain. The institute recommends that treatment should consist of exercise, psychological therapy and acupuncture, rather than analgesics. According to NICE, there is little or no evidence that drug treatment (including non-steroidal anti-inflammatory drugs, gabapentin and opioids) reduces pain or improves patients' quality of life.

To enable integration of evidence based alternative therapies, attitudes and systems need to be introduced, not only by the health authorities and health workers, but also by alternative therapists themselves. Necessary changes include the use of a common medical understanding and language, regulation of education and the introduction of research systems. A large proportion of acupuncturists still base their explanations and treatments, on traditional Chinese medical theories, instead of physiological mechanisms.

Anatomic mapping of meridians (channels that connect acupuncture points) has never been established. The term was probably an explanation of the nervous system in ancient China. Peripheral nerves are often localized in the same areas as meridians. Acupuncture points are localized in facia with a high concentration of nerve endings [22,23]. Research has shown that the effects of acupuncture are blocked when points are injected with a local anaesthetic, and when peripheral nerves are blocked [24]. MRI scans of the brain show specific responses related to the stimulation of specific points $[25,26]$. These findings indicate that both the central and the peripheral nervous systems are involved.

Evidence for the effect of acupuncture treatment is often clouded by placebo. Research control conditions, such as penetrating sham acupuncture and non-penetrating placebo needles, have been used in clinical trials investigating the effect of acupuncture in chronic pain syndromes. Such methods have been found to be surprisingly effective with regard to their analgesic properties. These findings have provoked a discussion as to whether acupuncture is merely a placebo. It is important to note that a significant placebo effect does not rule out the efficacy of the treatment [27]. Sham acupuncture involves a surface penetration with needles in areas with low concentrations of nerve endings. The method affects touch receptors, provoking changes in the limbic system [28], and is far from perfect as a control intervention. It is possible that this effect has been misunderstood to be a placebo or that the placebo associated with acupuncture is a 'true' placebo, in addition to limbic modulation. Thus, the comparison of active treatment and sham acupuncture may be an observation of two different key mechanisms. Current research is trending towards comparing the effects acupuncture to other evidence-based treatments, so called comparative effectiveness research, not only in the field of pain but in a wide range of conditions.

\section{High Time for a Change}

Chronic pain is a widespread and complex set of conditions that are often difficult and expensive to treat. International guidelines suggest a combination of treatments including medication, surgery, stimulation techniques, physiotherapy, psychological approaches and coping techniques [5]. There is no stipulation or suggestion of treatment priority, or indication as to whether treatments should be offered one after another, or simultaneously. Treatment packages, or individually tailored approaches are a possibility.

We also need to consider whether education interventions and plans for treatment and rehabilitation, should only involve the person with pain symptoms, or their partners and family as well? Also, since evidence-based medicine is often lacking in the field of chronic pain, is clinical expertise and experience enough? And, should complementary and alternative medicine routinely be offered to patients suffering from chronic pain? If so, should only evidencebased treatments such as acupuncture and chiropractic be offered, or should other treatment methods with emerging evidence, that supports their efficacy and safety be included?

Questions need to be answered. Broader aims of treatment need defining. To reduce the incidence of chronic pain in Norway we need to start thinking outside the box. 


\section{References}

1. Breivik H, Collett B, Ventafridda V, Cohen R, Gallacher D. Survey of chronic pain in Europe: prevalence, impact on daily life, and treatment. Eur $\mathrm{J}$ Pain. 2006; 10: 287-333.

2. Nielsen CS, Steingrimsdottir OA, Skurtveit SO. Folkehelserapporten. Langvarige smerter. Oslo: Folkehelseinstituttet. 2018.

3. Løyland B, Miaskowski C, Wahl AK, Rustoen T. Prevalence and characteristics of chronic pain among long-term social assistance recipients compared to the general population in Norway. Clin J Pain. 2010; 26: 624-630

4. World Bank Open Data. 2021

5. IASP Treede RD, Rief W, Barke A, et al. Chronic pain as a symptom or a disease: the IASP Classification of Chronic Pain for the International Classification of Diseases (ICD-11) PAIN. 2019; 160: 19-27.

6. Ried KJ, Harker J, Bala MM. Epidemiology of chronic non-cancer pain in Europe: narrative review of prevalence, pain treatments and pain impact. Curr Med Res Opin. 2011; 27: 449-462.

7. Legemeldt sykefravær etter diagnose og bosted. Oslo: NAV. 2019.

8. Ellingsen J. Utvikling i uførediagnoser per 31. desember 2015. Oslo: NAV. 2015.

9. Organisering og drift av tverrfaglige smerteklinikker. 2015

10. Brandon A, Kohrt J, Griffith L. Chronic pain and mental health: integrated solutions for global problems. Pain. 2018; 159: S85-S90.

11. Tauben D, Stacey BR. Approach to the management of chronic non-cance pain in adults. Literature review current through. 2021.

12. Bivirkningsrapporten 2018. Oslo: Statens legemiddelverk. 2018.

13. Moulin DE. Intravenous lidocaine in the management of chronic periphera neuropathic pain: a randomized-controlled trial. Can J Anaesth. 2019; 66 $820-827$

14. E Silva LOJ, Scherber K, Cabrera D. Safety and Efficacy of Intravenous Lidocaine for Pain Management in the Emergency Department: A Systematic Review. Ann Emerg Med. 2018; 72: 135-144.e3.

15. Hocking G, Cousins MJ. Ketamine in chronic pain management: an evidencebased review. Anesth Analg. 2003; 97: 1730-1739.

16. Derry S, Rice A Sc, Cole P. Topical capsaicin (high concentration) for chronic neuropathic pain in adults Cochrane Database Syst Rev. 2017; 1: CD007393.
17. Rosenquist RW, Benzon TH, Connis RT. Practice guidelines for chronic pain management: An updated report by the American Society of Anaesthesiologists task force on chronic pain management and the American Society of Regional Anesthesia and Pain Medicine. Anesthesiology. 2010; 112: 810-833.

18. Furlan $A D$, van Tulder $M$, Cherkin $D$, Tsukayama $H$, Lao $L$, Koes $B$, et al. Acupuncture and dry-needling for low back pain: an updated systematic review within the framework of the Cochrane Collaboration. Spine. 2005; 30 : 944-963

19. Linde K, Allais G, Brinkhaus B, Fei Y, Mehring M, Shin B-C, et al. Acupuncture for the prevention of tension-type headache. Cochrane Database Syst Rev. 2016; 4: CD007587.

20. Review and Analysis of Reports on Controlled Clinical Trials. Geneva: World Health Organization. 2003.

21. Chronic pain. Assessment and management. In development (GIDNG10069). London: National Institute for Health and Clinical Excellence (NICE), 2020.

22. Sakai S, Hori E, Umeno K, Kitabayashi N, Ono T, Nishijo H, et al. Specific acupuncture sensation correlates with EEGs and autonomic changes in human subjects. Auton Neurosci. 2007; 133: 158-169.

23. Chae Y, Chang DS, Lee SH, Jung W-M, Lee IS, Jackson S, et al. Inserting needles into the body: a meta-analysis of brain activity associated with acupuncture needle stimulation. J Pain. 2013; 14: 215-222.

24. Torsney C. Inflammatory pain neural plasticity. Curr Opin Phys. 2019; 11 51-57.

25. Toroski M, Nikfar S, Mojahedian MM, Ayati MH. Comparison of the Costutility Analysis of Electroacupuncture and Nonsteroidal Antiinflammatory Drugs in the Treatment of Chronic Low Back Pain. J Acupunct Meridian Stud. 2018; 11: 62-66.

26. Ren XJ, Chen HY, Wang BG, Zhao BX, Li SW, Zhang L, et al. Regiona homogeneity analysis on acupoint specificity with resting-state functional magnetic resonance imaging. Chin Med J (Engl). 2012; 125: 1627-1632.

27. Musial F. Acupuncture for the Treatment of Pain-A Mega-Placebo? Front Neurosci. 2019: 13: 1110

28. Lundeberg T, Lund I, Sing A, Naslund J. Is Placebo Acupuncture What It Is Intended to Be? Evid Based Complement Alternat Med. 2011; 2011: 93240. 